\title{
Analysis of Hearing and Tinnitus in Workers Exposed to Occupational Noise
}

\author{
Marlene Escher Boger ${ }^{1}$ \\ André Luiz Lopes Sampaio² \\ Carlos Augusto Costa Pires de Oliveira ${ }^{3}$
}

\begin{abstract}
Introduction: Noise is one of the harmful agents to health that is present in the various branches of economic activity. Hearing loss and tinnitus are among the most frequently reported complaints by workers exposed to occupational noise. Objective: To analyze the hearing and tinnitus in normal-hearing workers exposed to occupational noise. Method: This is a cross-sectional analytical trial in metallurgical industries, in which we evaluated normal-hearing workers through anamnesis, audiometry and otoacoustic emissions. Results: It was observed high prevalence of failure of otoacoustic emissions (40\%) and tinnitus (66.6\%). Both in the amplitude and in the signal-to-noise ratio, the higher is the frequency of the sound, the worse the results. Despite having audiometry within normal limits, the results indicate that workers are suffering the effects of exposure and reveals association between failure of otoacoustic emissions and tinnitus in this population $\left(\mathrm{X}^{2}=6,732\right)$. Conclusion: It is concluded that failures in DPOAE and tinnitus are predictors of hearing damage in normal-hearing workers.
\end{abstract}

Keywords: tinnitus; hearing loss, noise-induced otoacoustic emissions, spontaneous.

${ }^{1}$ Department of Health Sciences. University of Brasilia- Brasília -DF- Brazil. E-mail: marlene.escher@gmail.com

2Department of Otorhinolaryngology, Doc Med in Health Sciences. University of Brasilia. Brasília -DF-Brazil. E-mail: andremarjy@uol.com.br

${ }^{3}$ Department of Otolaryngology, Brasília University Medical School. University of Brasília. Brasília-DF -Brazil. E-mail: cacpoliveira@brturbo.com.br

Institution: University of Brasilia

Send correspondence to:

Marlene Escher Boger

Quadra 205, Lt 4, Bl B, Apt 302. Subdivision: Águas Claras.

City: Brasilia-DF. Brazil. Zip code: 71925-000. E-mail: marlene.escher@gmail.com

Paper submitted to the ITJ-EM (Editorial Manager System) on September 12, 2016;

and accepted on November 25, 2016. 


\section{INTRODUCTION}

Hearing health is being treated as a considerable economic and social importance matter, and this importance has grown steadily. Increasingly a wide variety of professionals shares interest on this subject. It is known that hearing loss interferes with the individual's quality of life, restricting their social interaction skills causing, in certain situations, constraints and stress. Thus, a movement among the scientific community has begun, not only for treatment but also for prevention of hearing health. Recent researches show the presence of mild hearing loss and reveal that commonly these changes are not detected in the battery of conventional audiological tests. Thus, other methods have been used to identify early hearing disorders such as, for example, testing the otoacoustic emissions (OAE) ${ }^{1,2}$.

Since it is a more sensitive method than pure tone audiometry, hearing monitoring by OAE may be indicated in Noise-induced hearing loss (NIHL) as its result can precede the onset of hearing loss in order to prevent the advance of loss. trials have been conducted in order to describe the changes and correlate the tone audiometry and otoacoustic emissions findings in individuals exposed to high-intensity noise. Researches show that serial conducting OAE in individuals exposed to noise can detect minute changes in cochlear function preceding the hearing loss on audiometry ${ }^{3-6}$.

It is known that workers exposed to noise mainly complain of difficulty recognizing speech and tinnitus. Tinnitus manifests itself as an endogenous auditory sensation, illusory, presenting itself as a sound that is perceived in the absence of external sound stimuli, called by many authors as ringing of the ears ${ }^{7}$. This auditory sensation is usually referred to as ringing, buzzing, whistling, roaring, humming, rain, among others, may be unilateral or bilateral, continuous or intermittent, constant, mono or polytonal ${ }^{8}$. It has variable intensity, and in its most severe form can be highly uncomfortable ${ }^{\text {. Currently, the }}$ tinnitus should be considered a pathological symptom or sequel of any aggression suffered by the auditory system.

Many authors agree that a sum of simultaneous and sequential causes can cause tinnitus, such as acoustic trauma, ototoxic drugs, hearing loss, vascular or metabolic problems, tumors, Meniere's disease and perilymphatic fistula, among others ${ }^{10}$. Among these, it is believed that $90 \%$ of cases are generated by changes in the inner ear. Despite recent scientific advances, tinnitus is a symptom wrapped in many unknowns and remains one of the challenges of audiology and otolaryngology areas. This is one of the main symptoms reported by workers exposed to occupational noise, noting therefore the relevance of the goal, which is to analyze the hearing and tinnitus in normal-hearing workers exposed to occupational noise.

\section{MATERIALS AND METHODS}

This is an epidemiological trial of cross-sectional analytical type, carried out in metallurgical industries, with noise levels above $85 \mathrm{~dB}$, during which we evaluated the hearing threshold, the Distortion product otoacoustic emissions test (DPOAE) and, through occupational anamnesis, occupational data, lifestyle and aspects related to morbidity were identified. The trial population was selected by convenience sample, composed only by companies that agreed to participate. These companies are geographically restricted to the Federal District/ Brazil. Workers aged between 18 and 55 years old were evaluated, all male and with at least one year of work in the function. Workers in sectors where there is no exposure to occupational noise above $85 \mathrm{~dB}$ did not participate in the research, workers with history of hearing loss of conductive or mixed type and workers with acoustic trauma history.

The distribution of sound intensity of the production plant of the evaluated metallurgical industries has been verified. For this, we used a sound pressure level meter (sonometer) properly calibrated and located in central points of the plant. The audiological evaluation was preceded by otoscopy and acoustic rest of 14 hours. Such evaluation was made to check the minimum response level for frequencies of $250 \mathrm{~Hz}, 500 \mathrm{~Hz}, 1 \mathrm{kHz}, 2 \mathrm{kHz}$, $3 \mathrm{kHz}, 4 \mathrm{kHz}, 6 \mathrm{kHz}$ and $8 \mathrm{kHz}$. Participants evaluated with the Distortion product otoacoustic emissions test (DPOAE) presented auditory thresholds equal to or less than $25 \mathrm{~dB}$ (within the normal bilateral standards).

The otoacoustic emissions test was performed in a silent room, in order to specifically evaluate the functionality of outer hair cells. DPOAE were evaluated by the simultaneous presentation of two different pure tones ( $F 1$ and $F 2$ ), expressed by the ratio of 1.22 . We used the intensity parameter $L=65$ and $L=55 \mathrm{~dB}$, being measured in the cochlea conditions with the frequencies $1,5 \mathrm{KHz}, 2 \mathrm{kHz}, 3 \mathrm{kHz}, 4 \mathrm{kHz}, 5 \mathrm{kHz}$ and $6 \mathrm{kHz}$. The analyzes of DPOAE were made by frequency, following the amplitude criteria (DP) above $-5 \mathrm{~dB}$ and the signalto-noise ratio (SNR) above $6 \mathrm{~dB}$ (61). The occurrence of DPOAE response in a frequency was considered when the values set out in the two above criteria were observed in it. The criteria of this trial are based on recent trials conducted in patients with various types of sensorineural hearing losses, which have indicated as best DPOAE test protocol the $\mathrm{L} 1>\mathrm{L} 2$ ratio, or more specifically, $\mathrm{L} 1=65$ and $\mathrm{L} 2=55 \mathrm{~dB}^{11-14}$.

The audiological assessment information were stored in Microsoft Excel database, performing thus the statistical analysis (average, median, standard deviation and prevalence rate). For the analysis of the results, we used the statistical Student's t-test (for rating averages and standard deviation) and Fisher's exact test (to assess the prevalence), both with $95 \%$ of significance level. For association between variables, we used the chi-squared test. The post hoc analyzes were made using one-way ANOVA or paired t-test, according to the needs. This trial was approved by the Ethics Committee of the Faculty of 
Health Sciences of Universidade de Brasília (UnB).

\section{RESULTS}

342 evaluations of hearing thresholds (audiometry) were held, preceded by an occupational anamnesis. Of these, $150(43.8 \%)$ tests met the inclusion criteria of the research. Workers assessed with DPOAE present average age of 34.6 years (SD \pm 8.8 ); of which, $38.5 \%$ are aged up to 30 years.

According to the results obtained in obtained with Distortion product otoacoustic emissions (DPOAE), it was observed that $40 \%$ of the individuals showed changes in both ears. When evaluating each ear this variable showed that there were $43.3 \%$ of failures in the left ear and $45.3 \%$ in the right ear, characterizing lesion in the outer hair cells of the cochlea even with audiometric thresholds within normal limits. There was no statistically significant association between laterality of the ears (right or left) and the presence of failure $(p=0.816)$ (Figure 1$)$.

By analyzing the general average of the amplitudes and the signal-to-noise ratio, the laterality of the ears and the evaluated frequency of DPOAE, it is observed that with increasing frequency there is a reduction of the amplitudes (Table 1). The post hoc analysis showed that the frequencies from 5 to $6 \mathrm{kHz}$ had averages significantly lower compared to other frequencies $(p<0.045)$.

During the assessment for occurrence of tinnitus among workers with normal hearing, who were submitted to the test of DPOAE and failed the test in at least one ear, we found a prevalence of $66.6 \%$. Among these, $41.5 \%$ reported feeling the symptom often and $58.5 \%$ say that tinnitus occurs rarely. As for laterality, it was found that the highest prevalence occurs in both ears $(41.5 \%)$, left ear and right ear respectively (30.2\% and $28.3 \%)$. There was no statistically significant difference between the ears ( $p$ $>0.05$ Student's t-test) (Tables 2 and 3).

\section{DISCUSSION}

The possibility of early identification of cochlear changes in normal-hearing workers led many scientists researching the effects of hearing caused by occupational noise through the OAE test. The choice of distortion products for this research was based on the possibility of evaluating the cochlear activity in specific frequencies,

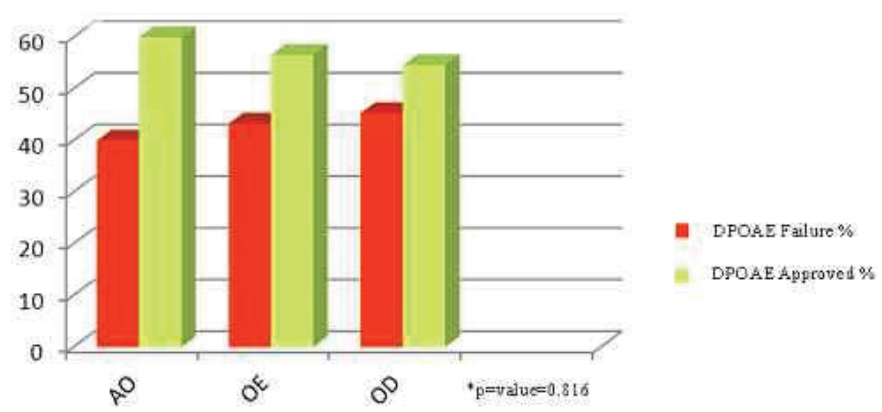

Figure 1. Prevalence of changes in DPOAE according to the result of the test and the laterality of the ears.
Table 1. Average of amplitude ratio and signal-to-noise ratio of the altered DPOAE, according to laterality (right ear) and the evaluated frequencies.

\begin{tabular}{|c|c|c|c|c|}
\hline \multicolumn{5}{|c|}{ DPOAEs } \\
\hline \multirow[b]{2}{*}{ Frequency (kHz) } & \multicolumn{2}{|c|}{ Amplitude } & \multicolumn{2}{|c|}{ Signal-to-Noise } \\
\hline & LE & RE & LE & $\mathrm{RE}$ \\
\hline 1.5 & 2.6 & 3.2 & 11.9 & 13.1 \\
\hline 2 & 3.6 & 4.1 & 13.7 & 14 \\
\hline 3 & 0.6 & 0.5 & 15.8 & 16.1 \\
\hline 4 & -3.2 & -2.9 & 14.1 & 14.2 \\
\hline 5 & -3.1 & -2.9 & 14.2 & 13.4 \\
\hline 6 & -8.1 & -7.9 & 13.6 & 13.9 \\
\hline *Frequency Factor $p<0.001$ & \multicolumn{4}{|c|}{ * 5 and $6 \mathrm{KHz}(\mathrm{p}<0.045)$} \\
\hline
\end{tabular}

Table 2. Prevalence of tinnitus among normal-hearing workers who failed DPOAE according to temporality and laterality of the symptom.

\begin{tabular}{cc}
\hline Tinnitus & Percentage (\%) \\
\hline Yes & 66.6 \\
No & 33.4 \\
\hline Temporality & Percentage (\%) \\
\hline Frequent & 41.5 \\
Rarely & 58.5 \\
\hline Laterality & Percentage (\%) \\
\hline RE & 28.3 \\
LE & 30.2 \\
BE & 41.5 \\
\hline
\end{tabular}

$(p>0.05$ Student's t-test)

Table 3. Tinnitus and otoacoustic emissions. Otoacoustic emission

\begin{tabular}{cccc}
\hline Tinnitus & Approved $(\mathrm{N})$ & Failure $(\mathrm{N})$ & Total $(\mathrm{N})$ \\
\hline Presence & 30 & 40 & 70 \\
Absence & 60 & 20 & 80 \\
Total & 90 & 60 & 150 \\
$* \mathrm{X}^{2}>3,841$ & & $\mathrm{X}^{2}=6,732$ & \\
\hline
\end{tabular}

providing comprehensive analysis compared to transient emissions which evaluates the cochlea globally ${ }^{15}$.

Recognizing that DPOAE may represent an important technical feature of prevention of NIHL, we used this hearing assessment procedure in order to investigate the cochlear conditions of metalworkers, since they are professionals present in auditory risk environment. It is confirmed that for this test is essential that the middle ear is in appropriate physiological conditions ${ }^{16,20}$ and that it is an efficient, fast and objective examination for the differential diagnosis and monitoring of NIHL as the audiometry, because it is subjective and depends directly on the worker response, may have disadvantages in the detection of responses ${ }^{17}$ and therefore it is subject to influences such as fatigue, pain, malaise, stress, inattention, examination misunderstanding, among others. However, it is considered that the audiometry is extremely important, because it shows the type and degree of hearing loss and that such a test should not be disregarded, but it should be supplemented by another test that adds objectivity to the result.

As for the auditory characteristics, it is observed 
that even with normal audiometric thresholds, $40 \%$ of workers have changes in DPOAE in both ears. The high prevalence found in this trial is corroborated by other authors that demonstrate the test sensitivity in detecting early cochlear alterations caused by noise exposure, which are not identified by audiometry ${ }^{18,19}$. By analyzing the average of the amplitudes and the signal-to-noise ratio of DPOAE, it was found that in both ears the averages decreased when increasing frequency. This finding was also obtained in other trials ${ }^{6,20}$.

As the occurrence of tinnitus in individuals without loss in conventional audiometry, researchers believe that this could be explained by diffuse damage of up to $30 \%$ of the outer hair cells throughout the spiral of the cochlea, with no impairment to the hearing threshold at frequencies from $250 \mathrm{~Hz}$ to $8 \mathrm{kHz}^{21}$. The results corroborate the findings of Hall and Haynnes, who claim that individuals with tinnitus and normal hearing in the conventional frequency range may have worse hearing thresholds at high frequencies and failures in the $\mathrm{EOA}^{22}$. The high prevalence of tinnitus in this trial is corroborated by other authors who have proved that one of the causes of this problem is the exposure to noise and thus it is one of the first symptoms of hearing loss ${ }^{23}$, which in turn is the occupational health problem more prevalent in industrial environments ${ }^{24}$.

It was observed that, in most cases, tinnitus appears as a sound of "whistle". We suppose that this data will reveal the predominance of tinnitus in acute frequency as well as the presence of hearing damage, since the post hoc analysis showed that the frequencies from 5 to 6 $\mathrm{kHz}$ had averages significantly worse compared to other frequencies, suggesting cochlear injury in this frequency range. Some researchers agree that the frequency of $a$ higher prevalence of tinnitus is similar to the frequency of hearing loss ${ }^{21}$.

The results of this trial suggest that, beyond the realization of pure tone and vocal audiometry, conducting DPOAE should be incorporated in the battery of occupational hearing monitoring tests in order to diagnose early hearing loss and prevent the onset of NIHL and tinnitus in Brazilian workers. The adoption of this measure will benefit both the employee and the employer, since adapting a proposal in order to achieve effective prevention of occupational hearing loss means protecting the worker from illness and the employer from negligence. In Brazil, the NR7 of Ministry of Labor and Employment ${ }^{25}$ defines that the audiometric examination should be performed only in the frequencies from 500 $\mathrm{Hz}$ to $8 \mathrm{kHz}$, however, the number of workers exposed to high sound pressure levels demand the need to know and assess the risk that such exposure leads to health. Some trials suggest the realization of high-frequency audiometry (up to $20 \mathrm{kHz}$ ) for early detection of NIHL, and consider that if it is not feasible to apply high frequencies, another option would be the otoacoustic emissions test that evaluates the hair cells and can check higher frequencies, in addition to being an objective, fast and convenient test, because it is not necessary to its realization to be inside acoustically treated environments.

The fact is that even with the mandatory use of hearing protection and compliance with current legislation, researches continue to point high rates of occupational hearing loss, tinnitus and cochlear damage in workers exposed to noise. Faced with the challenge of trying to analyze broadly this subject, when thinking at the national level, it is believed that despite the growing number of researches, there is a lack of knowledge about the actual number of exposed workers and also an underreporting or not notification of cases, thus, making the data available on occupational accidents, particularly of acoustic traumas and diseases related to NIHL, in official statistics, unable to measure the impact of what is occupational exposure to noise in occupational epidemiology, however there are records indicating that in Brazil, deafness is the second leading cause of occupational disease, and the prevention and early detection are the best tools to combat this reality. It is noteworthy, therefore, the importance of mandatory reporting by health professionals as well as those responsible for public and private organizations and establishments of health and education.

\section{CONCLUSION}

It is concluded that DPOAE failure and tinnitus are predictors of hearing loss, which are associated in this population, suggesting that, even with normal audiometric thresholds, indeed there is a cochlear damage already.

\section{REFERENCES}

1. Barros SMS, Frota S, Atherino CCT, Osterne F. A eficiência das emissões otoacústicas transientes e audiometria tonal na detecção de mudanças temporárias nos limiares auditivos após exposição a níveis elevados de pressão sonora. Braz J Otorhinolaryngol. 2007;73(5):592-8.

2. Kemp DT. Otoacoustic emissions, their origin in cochlear function and use. Br Med Bull. 2002;63(1):223-41

3. Biro K, Nnoszek L, Prekopp P, Nagyiványi K, Géczi L, Gaudi I, et al. Characteristics and risk factors of cisplatin-induced ototoxicity in testicular cancer patients detected by distorsion product otoacoustic emission. Oncol. 2006;70(3):177-84

4. Korres GS, Balatsouras DG, Tzagaroulakis A, Kandiloros D, Ferekidou E, Korres S. Distortion product otoacoustic emissions in an industrial setting. Noise Health. 2009;11(43):103-10.

5. Seixas NS, Kujiawa SG, Norton S, Sheppard L, Neitzel R, Slee A. Predictors of hearing threshold levels and distortion product otoacoustic emissions among noise exposed young adults. Occup Environ Med. 2004;61:899-907.

6. Atchariyasathian V, Chayarpham S, Saekhow S. Evaluation of noise-induced hearing loss with audiometer and distortion product otoacoustic emissions. J Med Assoc Thai. 2008;91(7):1066-71.

7. Tzaneva L, Sarov A, Damianova V. Audiological problems in patients with tinnitus exposed to noise and vibrations. Central European Journal of Public Health. 2002;8(4):233 -5.

8. Hoth $\mathrm{S}$. On a possible prognostic value of otoacoustic emissions: A study on patients with sudden hearing loss. European Archives of Otorhinolaryngology. 2006;262(3):217-24.

9. Sakata T, Esaki Y, Yamano T, Sueta N, Nakagawa T. A comparação entre a sensação de plenitude auricular e zumbido em perda auditiva neurossensorial aguda. Int. J Audiol. 2008;47(3):134-40.

10. Kaltenbach JA, Afman CE. Hyperactivity in the dorsal cochlear nucleus after intense sound exposure and its resemblance to tone-evoked activity: a physiological model for tinnitus. Hear Res. 2000;140:165-72. 
11.Gorga MP, Neely ST, Dorn PA. Distortion product otoacoustic emission test performance for a priori criteria and for multifrequency audiometric standards.Ear Hear. 1999;20(4):345-62.

12. Mills DM. Interpretation of standard distortion product otoacoustic emission measurements in light of the complete parametric response. J Acoust Soc Am. 2002;112(4):1545-60.

13.Avan P, Bonfils P. Distortion-product otoacoustic emission spectra and high-resolution audiometry in noise-induced hearing loss. Hear Res. 2005; 209(2):68-75.

14.Dreisbach LE, Siegel JH. Level dependence of distortionproduct otoacoustic emissions measured at high frequencies in humans. $J$ Acoust Soc Am. 2005;117(5):2980-8.

15. NIOSH. Preventing Occupational Hearing Loss. A Pratical Guide National Institute for Occupational Safety and Health. 1996.

16. Coelho MSB, Ferraz JRS, Almeida EOC, Filho NA. As emissões otoacústicas no diagnóstico diferencial das perdas auditivas induzida por ruído. Rev CEFAC. 2010;12(6):1050-8.

17. Baradarnfar $\mathrm{MH}$, Karamifar $\mathrm{K}$, Mehrparvar AH, Mollasadeghi A, Gharavi M, Karimi G, et al. Amplitude changes in otoacoustic emissions after exposure to industrial noise. Noise Health. 2012;14: 28-31.

18. Fiorini AC, Fischer FM. Emissões otoacústicas por transiente evocado em trabalhadores expostos a ruído ocupacional. Distúrb Comun. 2000;11(2):167-91.

19.Alvarenga KF, Jacob LCB, Martins CHF, Costa AO, Coube CZV, Marques JM. Emissões otoacústicas produto de distorção em indivíduos expostos ao chumbo e ao ruído. Braz J Otorhinolaryngol. 2003; 69(5):681-9.

20. Oliveira TMT, Vieira MM; Azevedo MF. Emissões otoacústicas em trabalhadores normo-ouvintes expostos ao ruído ocupacional. PróFono Rev de Atualização Científica. 2001;13(1):17-22.

21.Valente JP, Pinheiro LA, Carvalho GM, Guimarães AC, Mezzalira R, Stoler $\mathrm{G}$. Evaluation of factors related to the tinnitus disturbance. Int Tinnitus J. 2012;17(1):21-5.

22. Hall JW, Haynes DS. Audiologic assessment and consultation of the tinnitus patient. Seminars in Hearing. 2001;22(1):37-49.

23.Palmer KT, Griffin HS, Syddall HE, Davis A, Pannett B, Coggon D. Ocupactional exposure to noise and the attributable burden of hearing difficulties in Great Britains. Occupational and environmental medicine. 2002;59:634-9.

24. Rabinowitz PM. Noise-induced hearing loss. Am Fam Physician. 2000;61:2749-60.

25.Brasil. Portaria no. 3.214 de 08/06/1978. Aprovação das Normas Regulamentadoras do Capítulo V, Título II, da Consolidação das Leis do Trabalho, relativas à Segurança e Medicina do Trabalho. 